\title{
Treating Children with ASD: The Perspective of Caregivers
}

\author{
Noor Breik ${ }^{1}$, I fan Kuo ${ }^{1}$, Shawn Bugden ${ }^{1}$, Michael Moffat ${ }^{2}$ and Silvia Alessi-Severini ${ }^{1}$ \\ ${ }^{1}$ College of Pharmacy, Rady Faculty of Health Sciences, ${ }^{2}$ Max Rady College of Medicine, Rady Faculty of Health Sciences, \\ University of Manitoba, Winnipeg, Manitoba, Canada.
}

Received, March 2, 2018; Revised, March 27, 2018; Accepted, May 1, 2018; Published, May 1, 2018.

\begin{abstract}
Purpose: Treatment of Autism Spectrum Disorders (ASD) is challenging. Parents/caregivers' perspective on the effectiveness of therapies and services available to their children is important but neglected in the literature on ASD. This study investigated such perspective through questionnaire-guided interviews with a group of parents in the province of Manitoba (Canada). A secondary objective of the study was to explore how health care professionals and specifically pharmacists can assist in providing better care to children with ASD. Methods: Informed consent was obtained from all participants. Data on diagnoses and prescribed medications were collected from medical charts. Parents/caregivers completed questionnaires during interviews scheduled at their convenience. Specific questions were asked to gather caregivers/parents' perspectives on the effectiveness of medications and non-pharmacological interventions in controlling symptoms experienced by their children. Information on access to education and health services was also assessed. Common themes were identified using thematic analysis. Results: All children attended school, 88\% were males, 50\% experienced eating/sleeping difficulties; 69\% reported Attention Deficit Hyperactivity Disorder comorbidity. Risperidone was reported to be effective in controlling aggressive behaviours. Methylphenidate and aripiprazole were often discontinued. Melatonin and occupational therapy services were said to be very useful. Access to behavioural therapy was often limited. Parents were concerned about lack of trained professionals in schools, limited understanding of their children's needs, and uncertainty for the future. Conclusions: Better education and awareness are necessary to help ASD children and their families. Pharmacists should explore opportunities to provide better services.
\end{abstract}

This article is open to POST-PUBLICATION REVIEW. Registered readers (see "For Readers") may comment by clicking on ABSTRACT on the issue's contents page.

\section{INTRODUCTION}

The challenges of parents caring for children with Autism Spectrum Disorders (ASD) are well recognized (1). A body of literature has explored parents' characteristics and experiences in terms of stress levels, quality of life, coping mechanisms and advocacy (2-4); however, the investigation of parents/caregivers' perspective on the effectiveness of treatments and services their children receive has been limited (5).

Disease management options, which include pharmacological and non-pharmacological therapies (e.g., behavioural, occupational, speech) can be an important part of a comprehensive plan to address patients' needs. Ultimately, the goals of ASD therapies are to (a) improve communication skills, (b) enhance social functioning, (c) improve adaptive skills, (d) reduce negative behaviors, and (e) strengthen academic functioning and cognition (6-8). Psychological symptoms such as irritability, aggressive behaviours, depression and anxiety as well as physical symptoms such as sleep and gastrointestinal disturbances can be caused by comorbidities that often accompany a diagnosis of ASD. These symptoms are often treated with medications with variable effectiveness, often introducing undesirable side effects (9). As a result, children with ASD are treated with polypharmacy regimens often off-label. ASD and Attention Deficit Hyperactivity Disorder (ADHD) co-occurrence, formally recognized only in the latest version of the Diagnostic and Statistical Manual of Mental Disorders (DSM-V), has presented clinicians with challenges in terms of effective treatments (10).

\footnotetext{
Corresponding author: Dr. Silvia Alessi-Severini, College of Pharmacy, Rady Faculty of Health Sciences University of Manitoba, 750 McDermot Avenue, Winnipeg, Manitoba, Canada, Email: Silvia.Alessi-Severini@umanitoba.ca
} 
Pharmacists are in a unique position to help caregivers of ASD children in counselling regarding the use of prescription and over-the-counter medications, particularly in the complexity of attempting to control a myriad of symptoms. Unfortunately, pharmacists are rarely included in the team of health professionals who routinely provide care to children with ASD (11).

This study aimed at 1) assessing parents/caregivers' perspective on the effect of ASD therapies on their children's well-being, 2) assessing frequency of ADHD-associated symptoms in ASD population, 3) describing therapies used in clinical practice in children with ASD and with ADHDcomorbid ASD 4) identifying unmet needs in this population in terms of services and support 5) exploring the role of pharmacists in providing services and reflect on how pharmacists in their everyday practice can help caregivers of ASD children.

\section{METHODS}

This was an observational study based on information collected through questionnaire-guided interviews with parents/caregivers of children with ASD attending the Neurodevelopmental Services (NDS) department at the Manitoba Adolescent Treatment Centre (MATC) in Winnipeg (Manitoba, Canada). Based on practical considerations regarding the size of the unit and the expected saturation of themes identifiable in the prepared questionnaire, the expected number of respondents was of 10 individuals. Because of the limited scope of the themes explored and the limited size of the sample this study was conceived a pilot study that could inform further larger scale investigations on the perspective of caregivers of children with ASD on the themes of effectiveness of medications and services. Medical chart reviews were also conducted to collect data about therapies received by the children whose parents/caregivers entered the study.

Information regarding enrollees' perspective on their children's therapies was collected by means of questionnaire-guided interviews, which were conducted by the principal investigator and took place at sites and times convenient for the participants. Participants were offered a small honorarium as compensation for their time. No identifying information was collected and all data stored were de-identified. Data were collected between February 2015 and November 2015. The questionnaire included questions aimed at collecting information regarding 1) demographics (e.g., age, sex, area of residence, and primary caregiver), 2) child's symptoms with special attention to ADHD symptoms, as per Canadian Attention Deficit Hyperactivity Disorder Resource Alliance (CADDRA) guidelines (12), 3) parameters of quality of life "general well-being" (e.g., eating, sleeping patterns and school attendance), 4) therapies tried and currently used such as pharmacological therapies (prescribed and non-prescribed medications, e.g., stimulants, antipsychotics, over-the-counter (OTC) medications, supplements, natural health products and herbal remedies) and non-pharmacological (e.g., behavioural, occupational, speech therapy). Questions about physicians' visits and general support (e.g., school, family and financial support) were also included as a section for open ended comments. Specific questions were designed to stimulate comments and suggestions, and to facilitate the categorization into common themes.

Mixed qualitative/quantitative methods were employed to analyze data after conducting all interviews and collecting all data. Qualitative data were necessary to capture the full response of parent/caregiver perspective. Descriptive statistics were used to analyze quantitative data including demographic characteristics and medication use; questionnaire responses were analyzed by thematic analysis. While several approaches can be used in identifying themes (13-15), explicit topic area strategies were employed in the study. The questionnaire included guided topics and thorough discussion with the participants, study themes could be categorized as (i) symptoms comments, (ii) therapies comments, (iii) services/support comments and (iv) school support comments. (Please refer to the questionnaire in the attached Appendix 1)

In addition, comments provided by participants as a result of open-ended questions or spontaneously offered were organized and analysed by a) reading the comments accurately,

(b) identifying common themes, (c) collecting common sentences from all transcripts,

(d) segmenting them into manageable parts under each topic theme (category), (e) interpreting and describing the meaning of the extracted theme.

\section{Ethics}

Ethics approval was obtained from the Health Research Ethics Board (HREB) at the University of Manitoba (H2014:392). Permissions was also 
obtained from the clinic and the department attended by the children. Consents to be contacted were obtained from parents or guardians of children with ASD diagnosis via the treating physicians at the clinic. Individuals who agreed to be contacted received a phone call to confirm their interest in participating in the study. Signed informed consents were collected from all participants.

\section{RESULTS}

\section{Demographics}

Fourteen (14) participants completed the study, which resulted in data collected for 16 children. Children were between the age of 8 and 15 years. They were all enrolled in school (grade 2 to grade 9) at the time of the study, and approximately $69 \%$ were involved in some form of extracurricular activities (Table 1). Most children were taken care for by both parents, with one child in foster care. Others were taken care by single mothers.

Table 1. Demographic characteristics of children diagnosed with ASD ( $\mathrm{N}=16)$

\begin{tabular}{|c|c|}
\hline \multicolumn{2}{|l|}{ Characteristics } \\
\hline Males, n (\%) & $14(87)$ \\
\hline Age, mean (SD) & $10.8(1.9)$ \\
\hline Urban area of residence, $\mathrm{n}(\%)$ & $14(87)$ \\
\hline \multicolumn{2}{|l|}{ Primary caregiver, $\mathrm{n}(\%)$} \\
\hline both parents & $10(63)$ \\
\hline single parent & $5(31)$ \\
\hline Age of ASD diagnosis, mean (SD) & $4.4(1.9)$ \\
\hline Co-morbid ADHD, n (\%) & $11(69)$ \\
\hline School enrolment, $\mathrm{n}(\%)$ & $16(100)$ \\
\hline \multicolumn{2}{|l|}{ School support, n (\%) } \\
\hline EA.FT & $8(50)$ \\
\hline EA.PT & $5(31)$ \\
\hline \multicolumn{2}{|c|}{$\begin{array}{l}\text { Legend: EA.FT }=\text { education assistant full-time. } \\
\text { EA.PT=education assistant part-time } \\
\text { Age= age at the time of interview. Urban area in } \\
\text { Manitoba include only the cities of Winnipeg and } \\
\text { Brandon. }\end{array}$} \\
\hline
\end{tabular}

\section{Co-morbidities and medication use}

Severity of ASD symptoms were not systematically collected. Children in our sample represented a range from medium to high function. ADHD was the most common co-morbidity (69\%), other co-morbidities included anxiety, Tourette's disorder and nocturnal enuresis. Children in our study were struggling with sleeping (50\%) and eating (56\%) patterns (either overeating or being "picky eaters"); approximately $38 \%$ had gastrointestinal (GI) irregularities.

The most used prescription medication was risperidone: 9 out of 16 children had tried it and 6 were still on it at the time of the interviews. Caregivers' perspective was that this agent was effective in controlling aggression, irritability and difficulties with sleep. Aripiprazole had been tried by 8 of the 16 children but only 3 were still taking it at the time of the study. Methylphenidate controlledrelease (CR) (Biphentin ${ }^{\circledR}$ ) had been tried by 8 children but none of them was using it at the time of the interview. Reasons for discontinuation were dislike of taste/texture as well as negative effects on sleep and appetite. Short-acting methylphenidate (Ritalin $\AA$ ) had been tried by 7 out of 16 children but used by only 2 children at the time of the interview. Antidepressants were also tried by 5 children, and 4 were still taking antidepressants: citalopram (2), paroxetine (1) and sertraline (1). Clonidine was reported to be effective in helping children settle down at bed time (31\% were taking it). The most commonly used non-prescription medication was melatonin, with $50 \%$ of the children taking it on a regular basis. One child was following the advice of a naturopath who had found the child had sensitivity to dairy and eggs. Avoiding such foods seemed to have brought improvements in GI tract symptoms. Almost all patients had their prescription medications covered by insurance (fully $81 \%$ or partially $13 \%$ ).

\section{Non-pharmacological interventions and general support}

Non-pharmacological therapies were widely used in our sample of children: occupational therapy (OT) was the most "tried" and/or "currently used" therapy (10 children out of 16), followed by speech therapy (9 out of 16) and applied behavioural analysis (ABA) (7 out of 16). Most of the non-pharmacological approaches were covered by insurance, but parents found quality of services to be variable and wished that more services were offered by the school system with more teachers trained in ABA. Nevertheless, support received in school was considered adequate for their children's needs by $70 \%$ of parents and $75 \%$ agreed that the school provided a supportive environment. It seemed that support from extended family was not optimal as only $37 \%$ of the responders said that their family completely understood their child's needs. The number of 
physician/specialist's visits varied significantly among patients from 0 up to 24 visits per year.

\section{Qualitative analysis}

Four common themes were identified in the interview responses using the explicit topic areas of symptoms, therapies, services, and school support. Comments were classified as suggestions, satisfied (positive) and unsatisfied (negative) comments (Table 2).

One additional theme that consistently emerged from the study was the need for more awareness in the community and a better understanding of the needs of children with ASD. Most children would experience agitation and irritability in crowded and noisy places, most would have issues with changes in routine and with attending social events. The needs for designated quiet areas in certain setting such as doctors' offices, pharmacies and diagnostic labs "when children need blood work done" was identified. Parents felt that more flexibility was important on the part of school staff in modifying protocols in order to accommodate the needs of all children. Parents found that the non-pharmacological interventions were mostly helpful, but worried about limited access to such therapies, in particular because of the fact that children might outgrow the maximum age for eligibility and for drawing meaningful benefits. Without greater awareness of the full range of the needs of children with ASD, older children and highly functional children might often fall through the cracks of the system. While parents had some positive comments regarding the support received by their children's schools, concerns were expressed in terms of difficulties in obtaining approval for education assistants and safe transport services. More education for teachers as well as more classroom programs to teach students about their peers with ASD was found to be desirable.

Table 2. Common themes

\begin{tabular}{|c|c|c|c|}
\hline Theme & Suggestions & Positive (satisfaction) & Negative (dissatisfaction) \\
\hline \multirow[t]{6}{*}{ Symptoms } & $\begin{array}{l}\text { More ASD awareness } \\
\text { needed } \\
\text { More understanding for } \\
\text { ASD children needs } \\
\text { More wide-spread use of } \\
\text { visual signs (at doctors' } \\
\text { offices, hospitals, } \\
\text { pharmacies, labs) }\end{array}$ & $\begin{array}{l}\text { Improvements in ASD } \\
\text { symptoms observed by } \\
\text { using Rx and non- } \\
\text { pharmacological therapies } \\
\text { Improvements observed in } \\
\text { general well-being } \\
\text { (sleeping, eating, GI tract } \\
\text { symptoms) by using various } \\
\text { therapies }\end{array}$ & $\begin{array}{l}\text { Children experience } \\
\text { agitation from changes in } \\
\text { routine (changes in general) } \\
\text { Children seem not to be } \\
\text { listening } \\
\text { Triggers of agitation are } \\
\text { noises, smells, crowded } \\
\text { places }\end{array}$ \\
\hline & $\begin{array}{l}\text { DSM-IV vs. DSM-V } \\
\text { changes need to be taken } \\
\text { into consideration }\end{array}$ & $\begin{array}{l}\text { Improvements in ASD } \\
\text { symptoms observed with } \\
\text { growing }\end{array}$ & $\begin{array}{l}\text { Overeating } \\
\text { Picky eaters (they would eat } \\
\text { only specific foods) }\end{array}$ \\
\hline & & $\begin{array}{l}\text { Improvement in ASD } \\
\text { symptoms observed after } \\
\text { the birth of a new sibling }\end{array}$ & $\begin{array}{l}\text { General difficulties } \\
\text { (sleeping and GI) }\end{array}$ \\
\hline & & $\begin{array}{l}\text { Child is responding to } \\
\text { therapies }\end{array}$ & $\begin{array}{l}\text { Children do not like group } \\
\text { activities (e.g., team sports) }\end{array}$ \\
\hline & & $\begin{array}{l}\text { Child likes reading, has a } \\
\text { high IQ, excellent school } \\
\text { performance }\end{array}$ & $\begin{array}{l}\text { Behaviours are hard to } \\
\text { predict or deal with, waiting } \\
\text { for the next crisis }\end{array}$ \\
\hline & & & $\begin{array}{l}\text { Experience hard times in the } \\
\text { summer, at Christmas, and } \\
\text { at parties }\end{array}$ \\
\hline
\end{tabular}


TABLE 2. Continued...

It is hard to convince, explain things and generally communicate with the child

Negative social experiences (no friends, not invited to other kids' parties, or playdates at their houses)

$\begin{array}{ll}\text { Therapies } & \begin{array}{l}\text { Non-pharmacological } \\ \text { therapies (ABA, OT) most } \\ \text { effective, but coverage } \\ \text { should be extended for older } \\ \text { children }\end{array} \\ & \text { Generic vs. brand name } \\ \text { medications interchanges } \\ \text { can be an issue for ASD } \\ \text { children } \\ \text { Extended insurance } \\ \text { coverage is required } \\ \text { Medical follow-up and } \\ \text { medication refill } \\ \text { processes should be } \\ \text { facilitated } \\ \text { Pharmacists should be more } \\ \text { informed on ASD } \\ \text { Access to physiotherapy/OT } \\ \text { for ASD children should be } \\ \text { made easier } \\ \text { Medical charts should keep } \\ \text { record of alternative } \\ \text { therapies used (e.g., natural } \\ \text { products, OTC, } \\ \text { homeopathy) } \\ \text { Parents' compliance, stress, } \\ \text { financial status are } \\ \text { important factors for the } \\ \text { success of ASD therapies }\end{array}$

Antipsychotic medications, risperidone and quetiapine found helpful to induce sleep to sleep and reduce agitation

ADHD medications helped in improving

Attention and overall performance

Melatonin was found to be helpful for sleeping issues ABA was found very helpful

OT, speech, massage therapy also very helpful
ADHD medications cause side effects disrupting sleep and appetite

Antipsychotic use increased child's weight

Medication taste, texture, side effects, cost, availability

Coverage provided only by private insurance

ABA, OT, speech therapies offered are not enough, there is a need for more sessions to receive benefits

High functioning children do not qualify for coverage (EA, OT, ABA)

Polypharmacy is an issue

Fluctuation in response is observed

ASD children are more sensitive to the effects of medications 
TABLE 2. Continued...

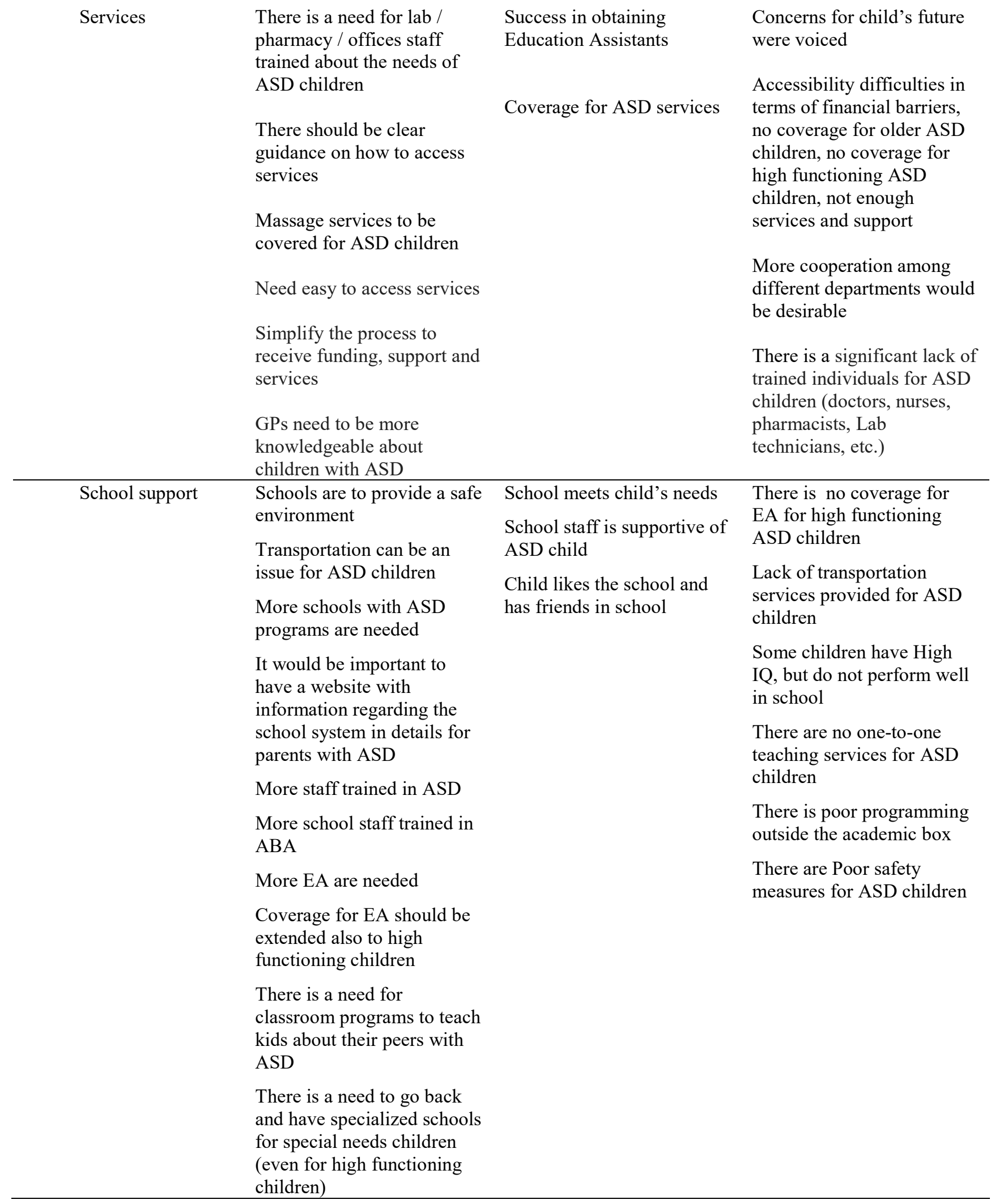




\section{DISCUSSION}

The experience of parenting a child with ASD can be overwhelming. While parents' stress and their roles as advocates for their children have been investigated (1-3), their perspective on what works and what does not in terms of their children' $s$ treatment has not been fully examined (5). This study reported the perspective of a small group of parents/caregivers in their assessment of various aspects of their children's treatment and well-being.

We observed a wide variation in participants' perception of their children's response to pharmacological therapies. This is due to the fact that individual responses can be influenced by many factors. Dose, side effects, combination with OTC medications, drug interactions vary among patients. Difficulties with follow-up with doctors and refill processes (e.g., booking appointments, getting refills) also play a role. Environmental changes (e.g., weather changes, holiday time, back-to-school time) can deeply affect ASD children's moods and behaviours. A switch from a brand name product to its generic alternative can be distressing for a child who is used to a certain shape or color. Our results regarding such factors are similar with what was shown in previous studies $(5,16-18)$.

Children in our sample were prescribed medications that had been evaluated in clinical trials (e.g., antipsychotics and ADHD medications) even though some do not have specifically approved pediatric indications. In Canada, most antipsychotics and antidepressants are not indicated for children and prescribing of psychotropic medications in ASD patients occurs largely off-label $(19,20)$. This is a difficulty that clinicians often face in treating young patients when evidence of medication efficacy is limited. Most caregivers appreciated that prescribed antipsychotics (i.e., risperidone) were effective in controlling symptoms of aggression but that they also helped with sleeping disorders, or that sedation might have been a welcome side effect at bedtime. While stimulants were certainly prescribed to try and control irritability and behavioural issues, likely to interfere with school attendance, it was generally recognized that they were not very effective and they would produced undesired effects (such as interference with appetite). None of the children had ever been treated with anxiolytics/hypnotics, such as benzodiazepines (e.g., alprazolam, lorazepam), buspirone, or zopiclone, drugs that are not fully evaluated for use in children and generally not recommended (21).

ABA was covered only until age 3 in Manitoba; in fact, from our results it appeared that if a child was diagnosed after the age of 3, access to ABA was problematic; however, this may change in the future as in the DSM-V the age restriction for ASD diagnosis was lifted (22). According to our caregivers, waiting time to get access to ABA services was of at least 2 years but no funding was available for highly functioning children. This is particularly problematic as a vast body of literature and guidelines $(6,7,23,24)$ support that early intervention is key in obtaining maximum benefit. Furthermore, it was noted that the number of ABAcertified staff was quite limited.

Our study was conducted on a limited number of participants who volunteered their time to complete relatively lengthy interviews. It is recognized that this sample may represent parents who were more highly involved with their children's health care and may not be representative of the general population in income or educational level. The results should be taken as exploratory and aimed at informing future larger scale studies that would reach families of a lower socio-economic status as well as refugees, aboriginal populations, new immigrants or families living in remote areas who might encounter more barriers to access services. Another limitation can be recognized in the uncertainty about generalization as insurance programs as well as accessibility to services vary from one health system to the other in different countries and even from one province to the other within the universal health care system of Canada. Furthermore, in our sample of 16 children only 2 were females; while this is consistent with the higher prevalence of ASD in males, our study did not provide the opportunity to assess sex differences in the terms of medication use and effectiveness as well as symptoms. It is possible that the high prevalence of ADHD observed was also a result of having an overwhelming majority of male subjects. Further studies are required to focus on caregivers of girls affected by ASD. Nevertheless, our study has strengths in term of accuracy of data regarding diagnoses, co-morbidities and therapies as it did not rely on surveys based on self-reported information, but were confirmed by reviewing patients' charts. This reduced the potential for recall bias to impact these aspects of the study results. While not a validated tool, the questionnaire administered through face-to-face interviews collected valuable 
comments that captured the importance of certain details that contribute to the effectiveness of medications and interventions (e.g., importance of texture, noise, delivery of instructions to children with ASD).

The major goal of an ASD management plan is to maximize the child's independence, functioning and quality of life $(6,7)$. Treatments for ASD should be individualized according to age, comorbid conditions, therapies previously tried, degree of impairment in social and behavioral function, and special needs of the child and his/her family (7).

The voices of parents and caregivers need to be heard as they can provide real-world evidence on what therapies and services are effective in improving their children well-being. Pharmacists can contribute in so many ways and help parents/caregivers of children with ASD. Pharmacists can find in their community pharmacies easy solutions to facilitate parents/caregivers in obtaining medications for their children and in reducing stress; understanding that children with ASD have difficulties waiting and may easily get agitated in public places, pharmacists can prioritize prescriptions for ASD children and/or offer delivery service; they can offer a noise/scent free waiting area. In addition, pharmacists should discuss with parents the option of enrolling their child in a maintenance medication system with an autoreminder, which means that the pharmacist will fill the child's prescription when due and will take care of contacting the doctor to get refills when needed. Pharmacists should document OTC/natural product therapies in the child's file, check for their safety and effectiveness, and counsel parents. They can also offer convenient blister pack options for multiple medications. Pharmacists need to be responsive to the challenges posed by any medication change that can be relevant for children with ASD such as changes in taste, texture, or color due to a change in product brand, or changes that are important to parents/caregivers such as costs and coverage issues. Pharmacists should become more aware of the needs of children with ASD and become an integral part of the team that cares for them. Ultimately all health care professionals, decision-makers and the public need to be well informed about parents and caregivers' needs and perspectives to make sure that therapies, services and support are available to them in order "to create better lives and opportunities" for their children (25).

\section{ACKNOWLEDGMENTS}

This study was funded through Dr. Alessi-Severini's operating grant at the University of Manitoba.

The authors have no conflict of interest to declare.

\section{REFERENCES}

1. Nicholas D.B., Zwaigenbaum L., Ing S., MacCulloch R., Roberts W., McKeever P., \& McMorris C.A. (2016). "Live it to understand it". Qualitative Health Research. 26, 291-934. doi:10.1177/1049732315616622

2. Boshoff K., Gibbs D., Phillips R.L., Wiles L., \& Porter L. (2016) Parents' voices: 'why and how we advocate'. A meta-synthesis of parents' experiences of advocation for their child with autism spectrum disorder. Child: care, health and development, 42(6), 784-797. doi:10.1111/cch.12383

3. McAuliffe T., Cordier R., Vaz S., Thomas Y., \& Falkmer T. (2017) Quality of life, coping style, stress levels, and time use in mothers of children with autism spectrum disorders: comparing single versus coupled households. Journal of Autism and Developmental Disorders, on line https://doi.org/10.1007/s10803-017-3240-z

4. Shivers C. M., Krizova K., \& Lee G. K. (2017) Types of strain among family members of individuals with autism spectrum disorder across the lifespan. Research in Developmental Disabilities 68, $42-51$.

5. Lake JK, Vogan V, Sawyer A, Weiss AJ, \& Lunsky Y. (2015) Psychotropic medication use among adolescents and young adults with an autism spectrum disorder: parent views about medication use and healthcare services. Journal of Child and Adolescent Psychopharmacology. 25, 260-268.

6. Myers SM. (2009) Management of autism spectrum disorders in primary care. Pediatric Annals 38, 42-49.

7. Maglione M.A., Gans D., Das L., Timbie J., Kasari C., \& for the Technical Expert Panel, HRSA Autism Intervention Research - Behavioral (AIR-B) Network. (2012) Nonmedical interventions for children with ASD: recommended guidelines and further research needs. Pediatrics 130 Suppl 2, S169S178.

8. Lai M. C., Lombardo M. V., \& Baron-Cohen S. (2014) Autism. Lancet 383, 896-910.

9. Kodish I., Rockhill C.M., \& Webb S.J. (2014) ASD: psychopharmacologic treatments and neurophysiologic underpinnings. Current Topics in Behavioural Neuroscience. 21, 257-275.

10. Musken J.B., Velders F.P., \& Staal W.G. (2017) Medical comorbidities in children and adolescents with autism spectrum disorders and attention deficit hyperactivity disorders: a systematic review. 
European Child and Adolescent Psychiatry - on line DOI 10.1007/s00787-017-1020-0

11. Horace AE and Ahmed F. (2015) Polypharmacy in pediatric patients and opportunities for pharmacists' involvement. Integrated Pharmacy Research and Practice. 4, 113-126.

12. Canadian Attention Deficit Hyperactivity Disorder Resource Alliance (CADDRA): Canadian ADHD Practice Guidelines, Third Edition, Toronto ON; CADDRA, 2011. http://www.caddra.ca_Accessed on July 31,2017

13. Hennink MM. (2007) "International Focus Group research" a Handbook for the Health and Social Sciences. Cambridge University ISBN978-0-52160780-3

14. Clarke, V., \& Braun, V. (2014). Thematic analysis. In Encyclopedia of critical psychology (pp. 1947-1952). Springer New York.

15. Rubin H and Rubin I. (2005) Qualitative interviewing: the art of hearing data. Sage -Research Methods http://dx.doi.org/10.4135/9781452226651

16. Matson JL and Hess JA (2011) Psychotropic drug efficacy and side effects for persons with autism spectrum disorders. Research in Autism Spectrum Disorders 5(1), 230-236

17. Aman MG, Novotny S, Samango-Sprouse C. (2004) Outcome measures for clinical trials in autism. CNS Spectr. 9:36

18. Aman MG, Farmer CA, Hollway J, Arnold LE. Treatment of inattention, overactivity, and impulsiveness in autism spectrum disorders. Child Adolesc Psychiatr Clin N Am 2008; 17:713
19. Nielsen ES, Rasmussen L, Hellfritzsch M, Thomsen PH, Norgaard M, Laursen T. (2017) Trends in offlabel prescribing of sedatives, hypnotics and antidepressants among children and adolescents $-\mathrm{a}$ Danish, nationwide register-based study. Basic \& Clinical Pharmacology \& Toxicology. 120, 360-367 (Doi: 10.1111/bcpt.12706)

20. Alessi-Severini S., Biscontri R.G., Collins D.M., Sareen J., \& Enns M.W. (2012) Ten years of antipsychotic prescribing to children: a Canadian population-based study. Canadian Journal of Psychiatry 57, 52-58.

21. Creswell C., Waite P., and Cooper P.J. (2014) Assessment and management of anxiety disorders in children and adolescents. Archives of Diseases in Childhood. 99, 674-678.

22. Halfon N. \& Kuo A.A. (2013) What DSM-5 could mean for children with autism and their families? JAMA Pediatrics, 167, 608-613.

23. National Research Council, Committee on Educational Interventions for Children with Autism. Educating Children with Autism, Lord C, McGee JP (Eds), (2001) National Academy Press, Washington, DC.

24. New York State Department of Health Early Intervention Program. Clinical practice guideline: The guideline technical report: Autism/Pervasive developmental disorders assessment and intervention for young children (age 0-3 years) (1999) Publication No. 4217, Albany, NY.

25. Autism Society Canada http://autismcanada.org/living-with-autism/ Accessed on August 2, 2017. 


\section{Appendix 1}

Questionnaire (DATE: dd/mm/yyyy)

Patient ID number:

\section{(1) Demographic characteristics}

\begin{tabular}{|c|c|}
\hline Question & Answer \\
\hline $1-$ Sex & Male ( ) Female ( ) \\
\hline 2-Age & \\
\hline 3-Age at ASD diagnosis & \\
\hline $\begin{array}{l}\text { 4-Any comorbid medical } \\
\text { conditions }\end{array}$ & $\begin{array}{l}\text { Yes ( ) specify............... } \\
\text { No ( ) }\end{array}$ \\
\hline 5-School & $\begin{array}{l}\text { No ( ) } \\
\text { Yes ( ) School grade ........... }\end{array}$ \\
\hline 6-School Support & $\begin{array}{l}\text { No ( ) } \\
\text { Yes ( ) }\end{array}$ \\
\hline 7-Area of residence & Urban ( ) Rural ( ) \\
\hline $\begin{array}{l}\text { 8- Number of siblings } \\
\text { and child order in the } \\
\text { family }\end{array}$ & $\begin{array}{l}\text { Yes ( ) ............... } \\
\text { Not Applicable ( ) }\end{array}$ \\
\hline 9-Primary caregiver & $\begin{array}{l}\text { ( ) Parents } \\
\text { ( )Other guardian .......... }\end{array}$ \\
\hline
\end{tabular}

\section{Comments:}




\section{(2) Symptoms}

\begin{tabular}{|c|c|c|c|c|c|c|}
\hline Questions & $\begin{array}{l}\text { Strongly } \\
\text { agree }\end{array}$ & Agree & Neutral & Disagree & $\begin{array}{l}\text { Strongly } \\
\text { disagree }\end{array}$ & Don't Know \\
\hline $\begin{array}{l}\text { 1-My child faces } \\
\text { difficulties in giving } \\
\text { close attention to } \\
\text { details }\end{array}$ & & & & & & \\
\hline $\begin{array}{l}\text { 2-My child faces } \\
\text { difficulties in sustaining } \\
\text { attention in play activiti }\end{array}$ & & & & & & \\
\hline $\begin{array}{l}\text { 3-My child loses his/her } \\
\text { things (toys, } \\
\text { books...etc.) and is } \\
\text { forgetful in daily } \\
\text { activities }\end{array}$ & & & & & & \\
\hline $\begin{array}{l}\text { 4-My child fidgets with } \\
\text { hands or feet }\end{array}$ & & & & & & \\
\hline $\begin{array}{l}\text { 5-My child runs or jump } \\
\text { excessively / has } \\
\text { difficulty to await his/he } \\
\text { turn }\end{array}$ & & & & & & \\
\hline $\begin{array}{l}\text { 6-My child has } \\
\text { difficulties in playing } \\
\text { quietly }\end{array}$ & & & & & & \\
\hline $\begin{array}{l}\text { 7-My child avoids direct } \\
\text { eye contact or seems to } \\
\text { not listen when spoken } \\
\text { directly }\end{array}$ & & & & & & \\
\hline $\begin{array}{l}\text { 8-My child gets annoyed } \\
\text { by others' requests; } \\
\text { he/she argues and } \\
\text { dislikes to obey orders }\end{array}$ & & & & & & \\
\hline $\begin{array}{l}\text { 9-My child deliberately } \\
\text { does things that annoy } \\
\text { other people }\end{array}$ & & & & & & \\
\hline $\begin{array}{l}10 \text {-My child is often } \\
\text { angry or vindictive }\end{array}$ & & & & & & \\
\hline
\end{tabular}

\section{Comments:}




\section{(3) General well being}

\begin{tabular}{|l|l|l|l|l|}
\hline \multicolumn{1}{|c|}{ Questions } & \multicolumn{1}{c|}{ Yes } & No & Sometimes & Comments \\
\hline $\begin{array}{l}\text { 1-My child has difficulties } \\
\text { sleeping }\end{array}$ & & & & \\
\hline $\begin{array}{l}\text { 2-My child has difficulties } \\
\text { with eating }\end{array}$ & & & & \\
\hline $\begin{array}{l}\text { 3-My child attends school } \\
\text { regularly }\end{array}$ & & & & \\
\hline $\begin{array}{l}\text { 4-My child is involved in } \\
\text { extracurricular activities }\end{array}$ & & & & \\
\hline $\begin{array}{l}\text { 5-My child often has gastro- } \\
\text {-intestinal issues } \\
\text { diarrhea /constipation) }\end{array}$ & & & & \\
\hline
\end{tabular}

\section{(4) Therapies}

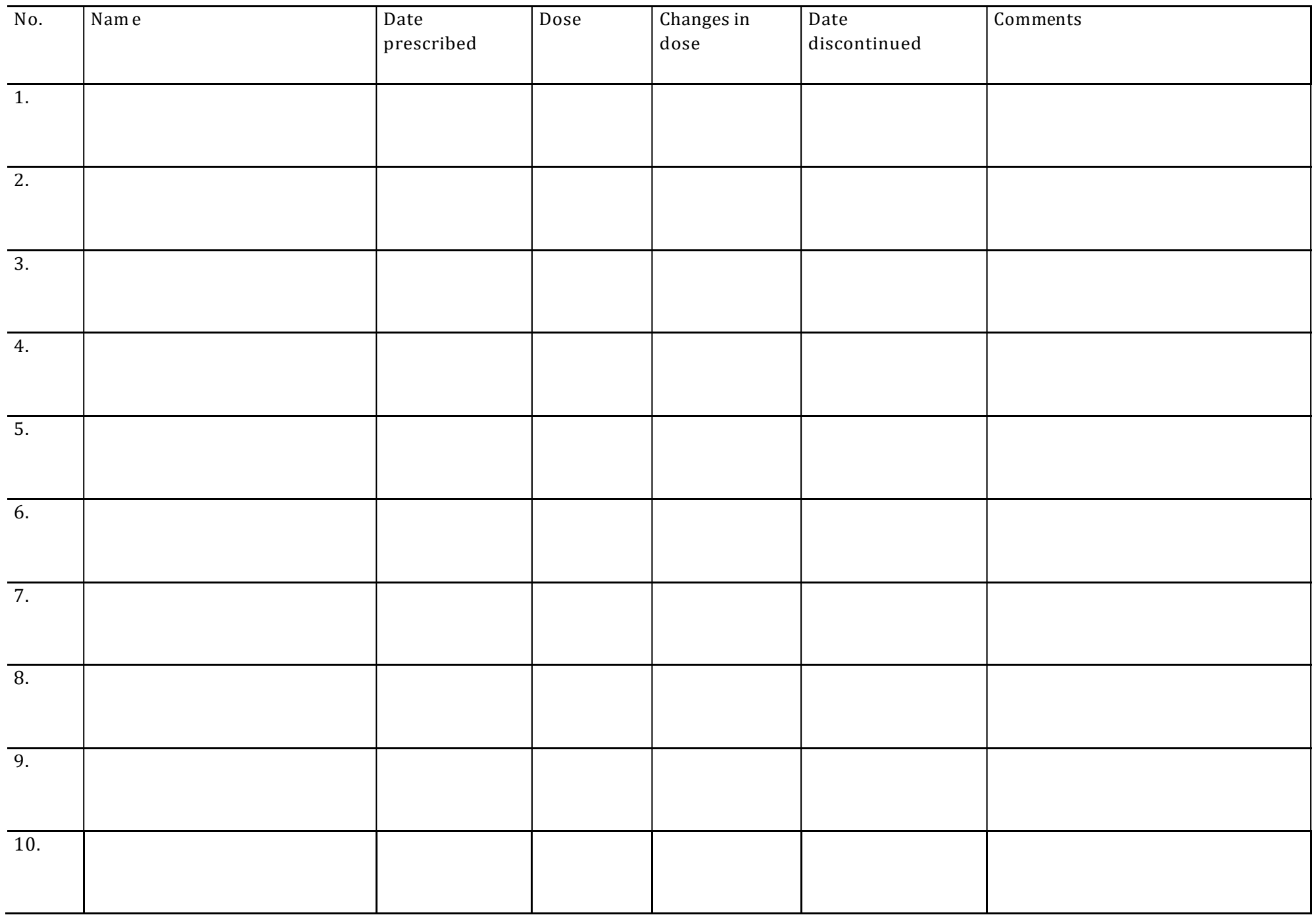

\section{Medications prescribed}




\section{2-Over The Counter (OTC) medications used}

\begin{tabular}{|c|c|c|c|c|c|c|}
\hline No. & Name & Dose & $\begin{array}{l}\text { Reason of } \\
\text { using }\end{array}$ & Date started & $\begin{array}{l}\text { Date } \\
\text { discontinued }\end{array}$ & Comments \\
\hline 1. & & & & & & \\
\hline 2. & & & & & & \\
\hline 3. & & & & & & \\
\hline 4. & & & & & & \\
\hline 5. & & & & & & \\
\hline
\end{tabular}

\section{3-Supplements/herbal products used}

\begin{tabular}{|c|c|c|c|c|c|c|}
\hline No. & Name & Dose & $\begin{array}{l}\text { Reason of } \\
\text { using }\end{array}$ & Date started & $\begin{array}{l}\text { Date } \\
\text { discontinued }\end{array}$ & Comments \\
\hline 1. & & & & & & \\
\hline 2. & & & & & & \\
\hline 3. & & & & & & \\
\hline 4. & & & & & & \\
\hline 5. & & & & & & \\
\hline
\end{tabular}

\section{4-Behavioral therapy received/prescribed}

\begin{tabular}{|c|c|c|c|c|c|c|c|}
\hline No. & Nam e/Type & Location & $\begin{array}{l}\text { Covered } \\
\text { Yes No }\end{array}$ & Date started & $\begin{array}{l}\text { Number of } \\
\text { sessions since }\end{array}$ & Date stopped & Comments \\
\hline \multicolumn{8}{|l|}{1.} \\
\hline \multicolumn{8}{|l|}{2.} \\
\hline \multicolumn{8}{|l|}{3.} \\
\hline \multicolumn{8}{|l|}{4.} \\
\hline 5. & & & & & & & \\
\hline & & & & & & & \\
\hline
\end{tabular}

\section{Comments:}


5 -Number of physician's (GP) visits per month

(0)

(1---4)

$>5$

6-Number of specialist's visits per month
$(1---4)$
$>5$

\section{Comments:}

\section{(5) Support}

\section{Support at school}

My child's school meets his/her needs

Yes No My child's

school helps the development of his/her skills

Yes No

(reading, communication, speaking..etc)

My child's school staff creates a supportive environment for my child Yes

No

\section{Family/Friends support}

Our Family/Friends understand my child's needs

Yes No

Our Family/Friends offer the help and support

Yes No

\section{Financial Support}

Our child's medications are covered by prescription insurance

Yes No

All services for our child are covered

Yes

No

\section{(6) Comments:}

* Do you have any comments you would like to add?

*Do you think there are more services needed or needing improvement 